National Energy Technology Laboratory

Strategic Center For Natural Gas (SCNG)

\title{
INSTRUMENTATION FOR SURVEYING ACOUSTIC SIGNALS IN NATURAL GAS TRANSMISSION LINES 5th Quarterly Report
}

Reporting Start Date: July 1, 2003

Reporting End Date: August 31, 2003

Principle Authors:

John L. Loth (304) 293-4111 ext 2343

jloth@mail.wvu.edu

Gary J. Morris (304) 293-4111 ext 2342

gmorris@mail.wvu.edu

(Mike) George M. Palmer (304) 293-4111 ext 2342

gmpalmer@mail.wvu.edu and graduate students:

Richard Guiler and Deepak Mehra

Report Issue Date: September 1, 2003

DOE Award Number: DE-FC26-02NT41324

\section{Submitting Organization:}

West Virginia University

Department of Mechanical and Aerospace Engineering

G-70 Engineering Sciences Building

Evansdale Drive

Morgantown, WV 26506

\section{SCNG Contact:}

Daniel J. Driscoll (304) 285-4717

daniel.driscoll@netl.doe.gov

Industrial Contact:

Brian C. Sheppard (304) 627-3733

Brian_C Sheppard@dom.com

At Dominion Transmission, Inc 


\section{Table of Contents}

Abstract 3

I. Introduction 4

II. Experimental 6

A. Instrumentation for Pipeline Acoustic Monitoring 6

B. Aerodynamic $\Delta \mathrm{P}$ Sensor Range Amplifier 9

C. Aerodynamic Step Function $\Delta \mathrm{p}$ Sensor Range Amplifier $\quad 10$

D. Aerodynamic Ramp Function dp/dt Sensor 12

E. Data Acquisition 13

III. Results and Discussion $\quad 14$

IV. Conclusions 14

V. References 17

\section{List Tables}

Table 1 - West Virginia University initial test schedule to record gas transmission line typical noise sources using the PAMP

\section{List of Figures}

Figure 1 - Schematic of 1000 psi gas leaking through a 2-D fracture with $60 \%$ streamline contraction, to create Mach 2 flow inside fracture, slowed by Mach discs but reaccelerated to Mach 3 outside pipe. Acoustic energy may also transfer past the sonic flow region via the boundary layer separation bubble to the gas inside.

Figure 2 - Oil theft detected acoustically within a $60 \mathrm{~km}$ stretch of pipeline. Upper plot is a wavelet transform at inlet, lower at outlet. A $20 \mathrm{~min}$ theft started at $3.00 \mathrm{pm}$, another at $3.24 \mathrm{pm}$. Data by Zhuang Li, College of Engineering, Tianjin U., China.

Figure 3 - The first generation of natural gas transmission line acoustic monitoring package weighed 94 pounds, which was abandoned because it was unmanageable for field-testing.

Figure 4 - Schematic of the Portable Acoustic Monitoring Package (PAMP)

Figure 5 - Second generation Portable Acoustic Monitoring Package (PAMP) weighing only 36 pounds including a remote battery pack, laptop with data acquisition and field table.

Figure 6 - Schematic of sensor response to a step function pressure transient.

Figure 7 - Free field corrections for the B \& K model 4133 and 4134 microphones operating characteristics.

Figure 8 - Steady differential pressure reading with needle valve $\mathrm{N}=1$ turn open, indicating the $\mathrm{dp} / \mathrm{dt}$ ramp function signal strength in inch of water.

Figures $9 \& 10$ - PAMP and data acquisition unit installed on a natural gas transmission line in West Virginia. Computer, shielded cables and plumbing tree are clearly visible. Figure 11 - Dominion Transmission Inc. 900-psi 24-inch transmission line access near Waynesburg, PA. Engineers Jim Parsons, Bill Ruffner, John Hart and WVU research assistant Richard Guiler next to the "Portable Acoustic Monitoring Package" (PAMP). 


\title{
Disclaimer
}

"This report was prepared as an account of work sponsored by an agency of the United States Government. Neither the United States Government nor any of their employees, makes any warranty, express or implied, or assumes any legal liability or responsibility for the accuracy, completeness, or usefulness any information, apparatus, product, or process disclosed, or represents that its use would not infringe privately owned rights. Reference herein to any specific commercial product, process or service by trade name, trademark, manufacturer, or otherwise does not necessarily constitute or imply its endorsement, recommendation, or favoring by the United States Government or any agency thereof. The views and opinions of the authors expressed herein do not necessarily state or reflect those of the United States Government or any agency thereof."

\begin{abstract}
In the U.S. natural gas is distributed through more than one million miles of highpressure transmission pipelines. If all leaks and infringements could be detected quickly, it would enhance safety and U.S. energy security. Only low frequency acoustic waves appear to be detectable over distances up to $60 \mathrm{~km}$ where pipeline shut-off valves provide access to the inside of the pipeline.

This paper describes a Portable Acoustic Monitoring Package (PAMP) developed to record and identify acoustic signals characteristic of: leaks, pump noise, valve and flow metering noise, third party infringement, manual pipeline water and gas blow-off, etc. This PAMP consists of a stainless steel $1 / 2$ " NPT plumbing tree rated for use on 1000 psi pipelines. Its instrumentation is designed to measure acoustic waves over the entire frequency range from zero to $16,000 \mathrm{~Hz}$ by means of four instruments: 1) microphone, 2) 3-inch water full range differential pressure transducer with $0.1 \%$ of range sensitivity, 3 ) a novel 3" to 100" water range amplifier, using an accumulator with needle valve and 4) a line-pressure transducer. The weight of the PAMP complete with all accessories is 36 pounds. This includes a remote control battery/switch box assembly on a 25 -foot extension chord, a laptop data acquisition computer on a field table and a sun shield.
\end{abstract}




\section{I. - INTRODUCTION}

Natural gas transmission lines transport dry clean natural gas at high pressure from field processing facilities to distribution centers. Gas from Texas and Louisiana is distributed all over the U.S in underground steel pipes ranging up to 42 inch in diameter. Thirty percent of the energy produced in the Unites States comes from natural gas supplied through more than one million miles of transmission lines. Corrosion of the pipe wall is a major cause of leaks. The number of leaks reported increases every year, from 533,000 in 1971 to 749,000 in 1975 (Parker, 1981). Crouch et al. 1999, lists the various types of mechanical damage which causes leaks; $44 \%$ due to construction equipment on the pipeline right of way, $13.5 \%$ due to follow up pitting corrosion and $8 \%$ due to earth movement during landslides and floods. DOT statistics from 1994-2001 lists 224 manmade third party incidents on transmission lines resulting in: 7 death, 35 injuries and $\$ 167$ million in property damage (Huebler, 2002). Leaks are very common and are classified as to the urgency of repair based on their potential danger. The first attempts to develop acoustic leak detection methods appeared in the 1930's. In that decade four publications appeared: Smith, 1933; Gilmore, 1935; Richardson 1935;Larson 1939. Parker 1981 wrote an excellent historical overview of the development of acoustic leak detection methods.

The appearance of a rupture, leak or damage usually generates an acoustic signal. The amplitude, frequency spectrum and attenuation behavior are a function of the pipeline and distance from the source. Sudden leaks produce a rapid change in fluid pressure. The associated pressure transient is often referred to as a burst signal (Bassim, 1994). A supersonic jet of escaping gas generates acoustic energy externally to the pipe with a wide frequency spectrum $(1 \mathrm{kHz}-1 \mathrm{MkHz})$, the majority of which is confined to the moderately high frequency portion $(175 \mathrm{kHz}-750 \mathrm{kHz})$, (Shack, 1980). When highpressure gas escapes through an opening in the pipeline wall, it accelerates to sonic speed at the minimum area. This sonic region inside the gas jet bars all externally generated acoustic waves from reaching the inside of the pipe via the gas itself and can only be transmitted to the inside via the subsonic boundary layer or the neighboring pipe wall.

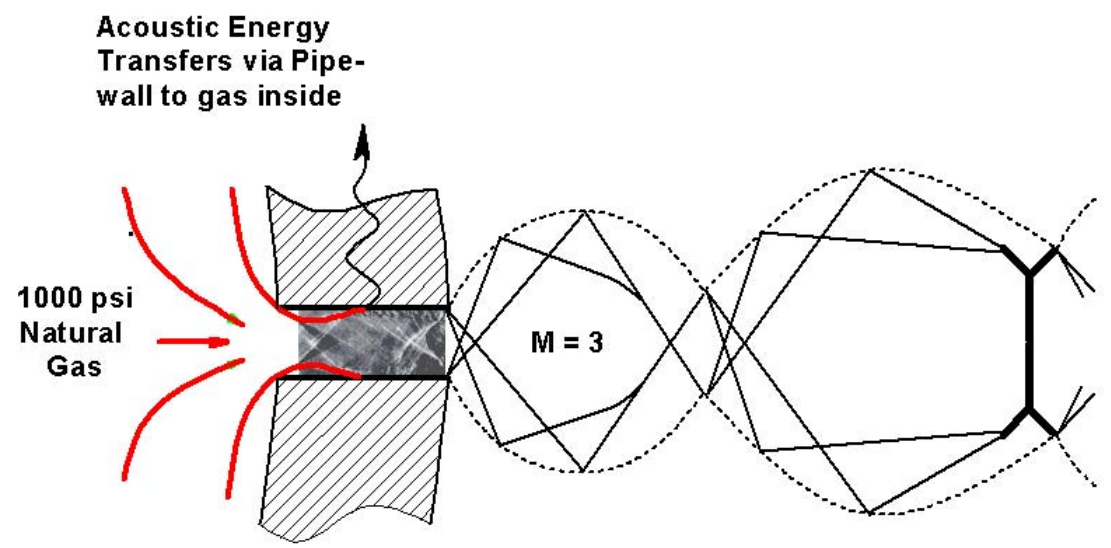

Figure 1 - Schematic of 1000 psi gas leaking through a 2-D fracture with $60 \%$ streamline contraction, to create Mach 2 flow inside fracture, slowed by Mach discs but reaccelerated to Mach 3 outside pipe. Acoustic energy may also transfer past the sonic flow region via the boundary layer separation bubble to the gas inside. 
Due to the intimate contact of the pipeline wall with the backfill material, acoustic energy within the wall does not travel far. Damping in proportion to the square of the frequency impedes transmission of acoustic signals through gas. Viscous effects, walldamping effects, and molecular relaxation all contribute to the attenuation of high frequency acoustic signals. Rocha, 1989 found that only relatively low frequencies acoustic signals are useful for practical leak detection methods. Acoustic frequencies on the order of $10 \mathrm{~Hz}$ can propagate in the gas for distances on the order of 100 miles. The amplitude of the wave is then related to the properties of the gas, the pressure at which the pipeline is operated and the size of the leak. For a pipe without flow, the acoustic rarefaction wave strength $\Delta \mathrm{p}$ will equal the product of $30 \%$ of the pipeline pressure times the ratio of leak area to pipe area. Or the sudden opening of a $6.4 \mathrm{~mm}(1 / 4$ inch $)$ diameter hole in a $45.7 \mathrm{~cm}$ (18 inch) diameter pipe operating at 69 bars (1000 psi) would generate an acoustic $\Delta \mathrm{p}$ signal of $400 \mathrm{~Pa}$ equivalent to $20 \log _{10}(400 / 0.00002)=146 \mathrm{~dB}(0.06 \mathrm{psi}=$ 1.6 inch water). A gradual change in leak size, such as a result of corrosion is not distinguishable from a period of excessive demand, when the amount of gas stored (line pack) is allowed to drop. Therefore every transmission line operator uses a transient analysis code to monitor operations over the entire system. When interfaced with SCADA (Supervisory Control And Data Acquisition) system, the opportunity to locate leaks is far superior to mass balance methods.

A sudden developing leak induces a traveling pressure wave in the pipeline. Initially this wave is a step function $\Delta \mathrm{p}$, but due to friction this wave dissipates into a ramp function (Wiley 1993). To detect such a pressure rate of change requires monitoring $\mathrm{dp} / \mathrm{dt}$ instead of $\Delta \mathrm{p}$. Such systems are used on most large transmission lines today and are very reliable for the fast onset of large leaks of magnitude ranging from $0.5 \%$ to $10 \%$ of the flow (Jolly 1992). Kennedy, 1984 describes a large SCADA system monitoring a network of 23 pipelines covering 3000 miles. It requires monitoring over 20,000 status points every few seconds. This task is carried out by hubs of computers, each of which are monitored by hub master computers, which in turn report to a system master computer.

Jolly, 1992 reviewed several different acoustic based leak detection methods and found the most promising to be the low frequency impulse detection method. This could detect the creation of a one-inch hole over a distance of $100 \mathrm{~km}$. Rocha's paper 1989 “ Acoustic monitoring of pipeline leaks", is one of the most frequently referenced papers. He configured his pressure sensors to record leak induced pressure waves in the frequency range from $0.05 \mathrm{~Hz}$ to $10 \mathrm{kHz}$., because only such low frequency waves were capable of traveling the large distances between pipeline shut-off valves without excessive damping. Leis et al, 1998 found experimentally that low frequency acoustic signals attenuated at the rate of 1.6 to $3.2 \mathrm{~dB}$ per mile. Zhang, 1996 describes an acoustic leak detection study on a 2 foot diameter liquefied natural gas pipeline which was $220 \mathrm{~km}$ long. Ten different leaks were created with leakage rates ranging from 0.5 to $1.7 \mathrm{~kg} / \mathrm{s}$, but only leaks in excess of $1.6 \mathrm{~kg} / \mathrm{s}$ could be detected without false alarms. Acoustic detection of both the magnitude and location of a leak has been described in Qian's textbook, 2000. This is a wavelet detection method developed by Zhang Li at Tianjin University Peoples Republic of China shown in Fig. 2. 
By recording pressure, and flow rate all as a function of the GPS time signal at two line shut off valves located $60 \mathrm{~km}$ apart, he could detect the location and duration of a leak induced by oil thieves to fill up a tanker truck.

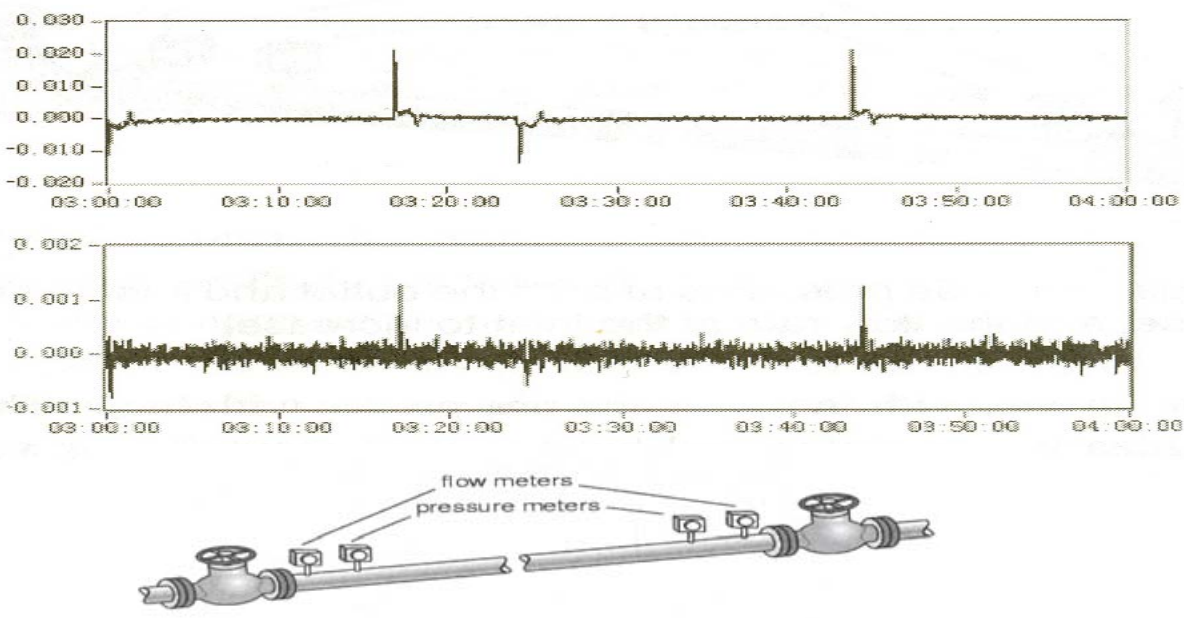

Figure 2 - Oil theft detected acoustically within a $60 \mathrm{~km}$ stretch of pipeline. Upper plot is a wavelet transform at inlet, lower at outlet. A 20 min theft started at $3.00 \mathrm{pm}$, another at 3.24 pm. Data by Zhuang Li, College of Engineering, Tianjin U., China.

\section{II. - EXPERIMENTAL}

\section{A. INSTRUMENTATION FOR PIPELINE ACOUSTIC MONITORING}

Encouraged by the successes reported in the literature with on-line leak detection, the WVU team developed a portable acoustic sensor package for pipeline acoustic monitoring. To identify acoustic signals emitted by a leak or $3^{\text {rd }}$ party infringement one must first identify the acoustic characteristic of flow associated with: valve operation, pump noise, flow metering orifices and water blow off. Dominion Transmission Inc, in Clarksburg WV has graciously allowed WVU access to some of their pipelines and helped in designing a safe sensor package. Access to the inside of the pipeline will be limited to $1 / 2$ "NPT test valves located near most shut-off valves. They are usually far apart, up to $60 \mathrm{~km}$. As acoustic signals above $1 \mathrm{kHz}$, traveling in a gas pipeline, dissipate in strength with the square of their frequency, one can expect to receive only signals in the low audible range and step or ramp type flow transients associated with valve opening/closing or sudden leaks. Rocha (1989) showed that the wave speed in natural gas pipelines is somewhere in between the isentropic and isothermal speed of sound. For methane with $\mathrm{R}=518 \mathrm{~J} / \mathrm{kgK}$ and $\mathrm{k}=1.3$, find the isentropic speed of sound at $\mathrm{T}=288^{\circ} \mathrm{K}$ is $a=\sqrt{\left(\frac{\partial p}{\partial \rho}\right)_{s}}=\sqrt{k^{*} R^{*} T}=456 \mathrm{~m} / \mathrm{s}$, isothermal speed $a=\sqrt{\left(\frac{\partial p}{\partial \rho}\right)_{T}}=\sqrt{R^{*} T}=386 \mathrm{~m} / \mathrm{s}$

Roche found the best approximation was a $=400 \mathrm{~m} / \mathrm{s}$. By recording a GPS based time base signal together with a leak induced acoustic signal, it is possible to pinpoint the location of the leak. For example when two acoustic wave sensors are placed a distance $\mathrm{L}(\mathrm{m})$ apart and one detects a leak $\Delta \mathrm{t}$ seconds before the other, the leak will be located a 
distance $0.5^{*}(\mathrm{~L}-\mathrm{a} * \Delta \mathrm{t})$ meter from sensor which first received the signal. For example if $\mathrm{L}=60,000 \mathrm{~m}$ and $\Delta \mathrm{t}=50$ seconds, leak is $20,000 \mathrm{~m}$ from station which first sensed the leak signal.

One needs at least a microphone and a differential pressure sensor capable of 1000 psi operating pressures. Even inexpensive capacitor type microphones can cover the range from $70 \mathrm{~Hz}$ to $16 \mathrm{kHz}$. Highly sensitive differential pressure sensors capable of tolerating 1000 psi over pressure are hard to find. The Rosemont Model 3051 with a software adjustable range down to 3 " water $(747 \mathrm{~Pa})$ has a $0.1 \%$ of span accuracy or 0.03 "water $(7.47 \mathrm{~Pa})$. In terms of decibel this is: $20 * \log \left(\Delta \mathrm{p}(\right.$ in Pa $\left.) /\left(\mathrm{P}_{\text {ref }}=0.00002 \mathrm{~Pa}\right)\right)=$ $91.4 \mathrm{~dB}$ (decibels). It has a frequency response up to $22 \mathrm{~Hz}$ and is enclosed in a NEMA 7 explosion proof housing. It is desirable to perform all testing with this instrument programmed at its maximum sensitivity. However, this will eliminate recording step function signals $\Delta \mathrm{p}$ in excess of its 3 " water range unless a range amplifier is added.

The first range amplifier developed was in the form of a 3" floating diaphragm, mounted inside a flanged 4" pipe nipple. A strain-gage was used to measure its displacement. The entire unit was supported on a $1 / 2$ " NPT nipple. This instrument package was mounted on the WVU blow down tunnel for in house testing see Fig. 3. Although all instruments worked as anticipated, the plumbing alone of this assembly weighed 94 pounds, which rendered this package totally unmanageable for field-testing.

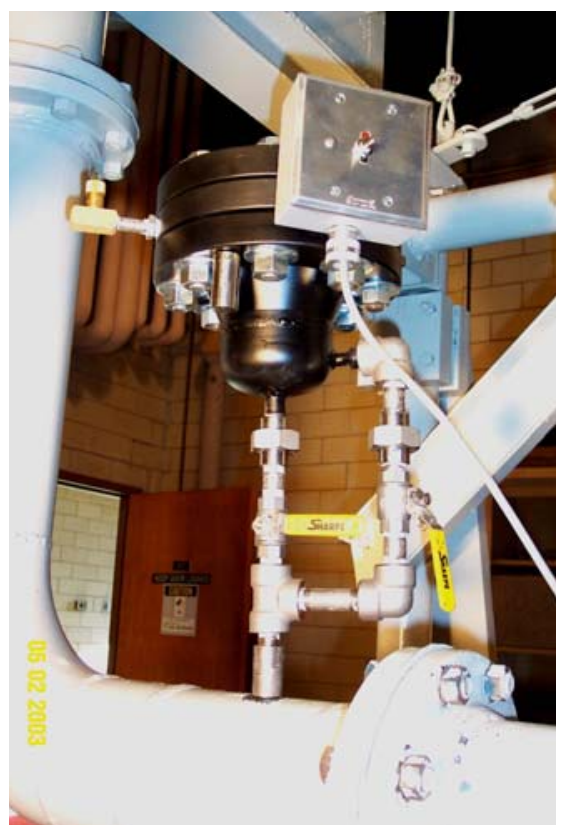

Figure 3 - The first generation of natural gas transmission line acoustic monitoring package weighed 94 pounds, which was abandoned because it was unmanageable for field-testing.

The second generation was a Portable Acoustic Monitoring Package (PAMP) designed with portability in mind. Only 1000 psi rated $1 / 2$ " NPT stainless steel fittings with some $1 / 4$ " fittings and 4500 psi rated flex hoses were used. A differential pressure range amplifier in the form of an accumulator with high precision needle valve, mounted in series with the differential pressure gage, replaced the 3" diaphragm. 
This (PAMP) consists of separate components; all together they weigh only 36 pounds. The main component is a $1 / 2$ " plumbing tree housing all the sensors, such as:

1) A $3 / 8$ " diameter capacitor microphone with $70 \mathrm{~Hz}$ to $16 \mathrm{kHz}$ linear response.

2) A $\Delta$ p sensor, with 1000-psi overload protection, Rosemont model 3051, with its 3 inch water operating range and sensitivity $0.1 \%$ of span equal $0.75 \mathrm{~Pa}$. or ( $91 \mathrm{~dB}$ ).

3) A high precision needle valve in series with a one-liter accumulator tank was added to extend the differential pressure operating range from 3 " water to 100 " water without loss in sensitivity.

4) A 1000-psi pipeline pressure gage.

5) A 10-psi differential pressure gage.

6) A remote aluminum battery/switch box connected to the plumbing tree by a 25 foot shielded extension chord was required to satisfy safety regulations.

7) A laptop with 4-channel PCMCIA type A/D converter and amplifier with data analysis software.

8) A folding computer/electronics platform with sunscreen completes the 36-pound package.

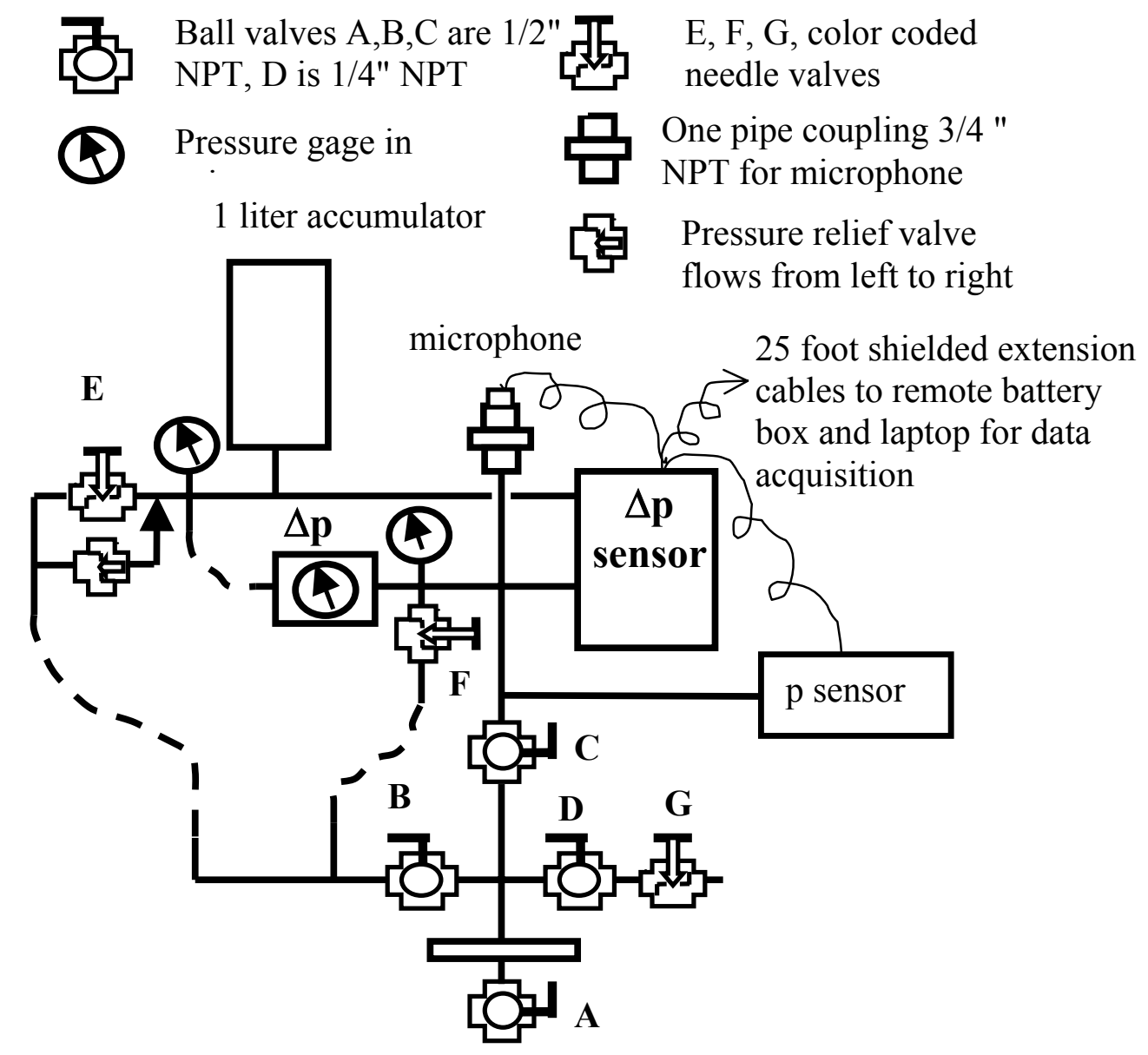

Figure 4 - Schematic of the Portable Acoustic Monitoring Package (PAMP) 


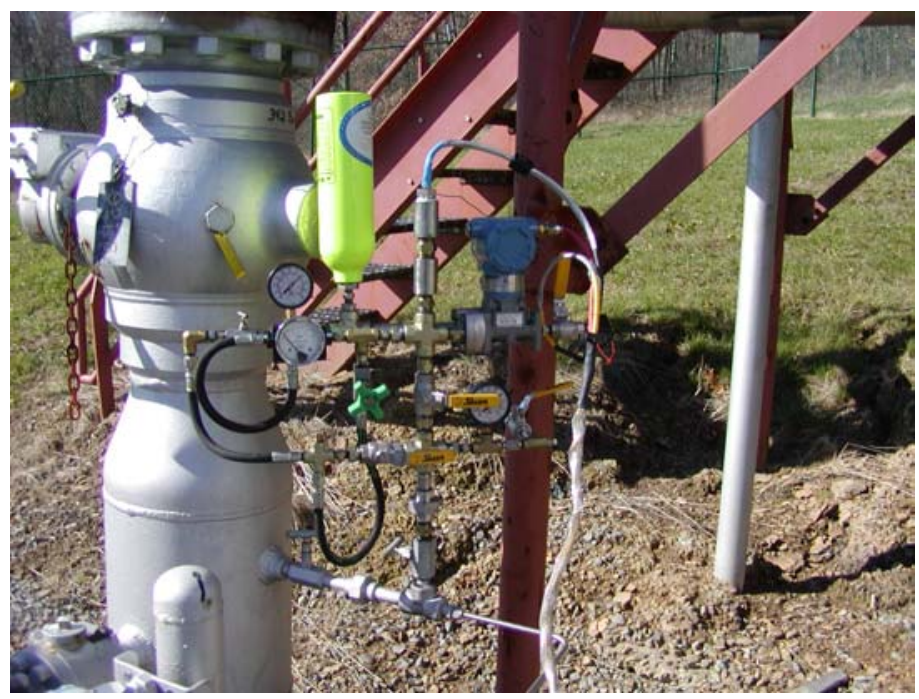

Figure 5 - Second generation Portable Acoustic Monitoring Package (PAMP) weighing only 36 pounds including a remote battery pack, laptop with data acquisition and field table.

\section{B. - AERODYNAMIC $\triangle$ P SENSOR RANGE AMPLIFIER}

To measure flow transients step functions in excess of the maximum sensitivity of the Rosemont model 3051 transducer with its $\Delta \mathrm{p}_{\max }=3$ " water differential pressure, a range amplifier was installed. This is in the form of a 1-liter accumulator with a precision 10 turn color-coded needle valve installed in series with the differential pressure transducer. With the needle valve closed there will be no range amplification. The range amplification depends on the color-coded needle valve opening in number of turns. When the flow transient signal exceeds the sensor range $\Delta \mathrm{p}_{\max }$, there will a time delay $\mathrm{t}_{\mathrm{c}}$ during which the sensor reads $\Delta \mathrm{p}_{\max }$. From measured time delay $\mathrm{t}_{\mathrm{c}}$ and the number of turns $\mathrm{N}$ valve is open, the amplitude of the incoming $\Delta$ p signal is calculated.

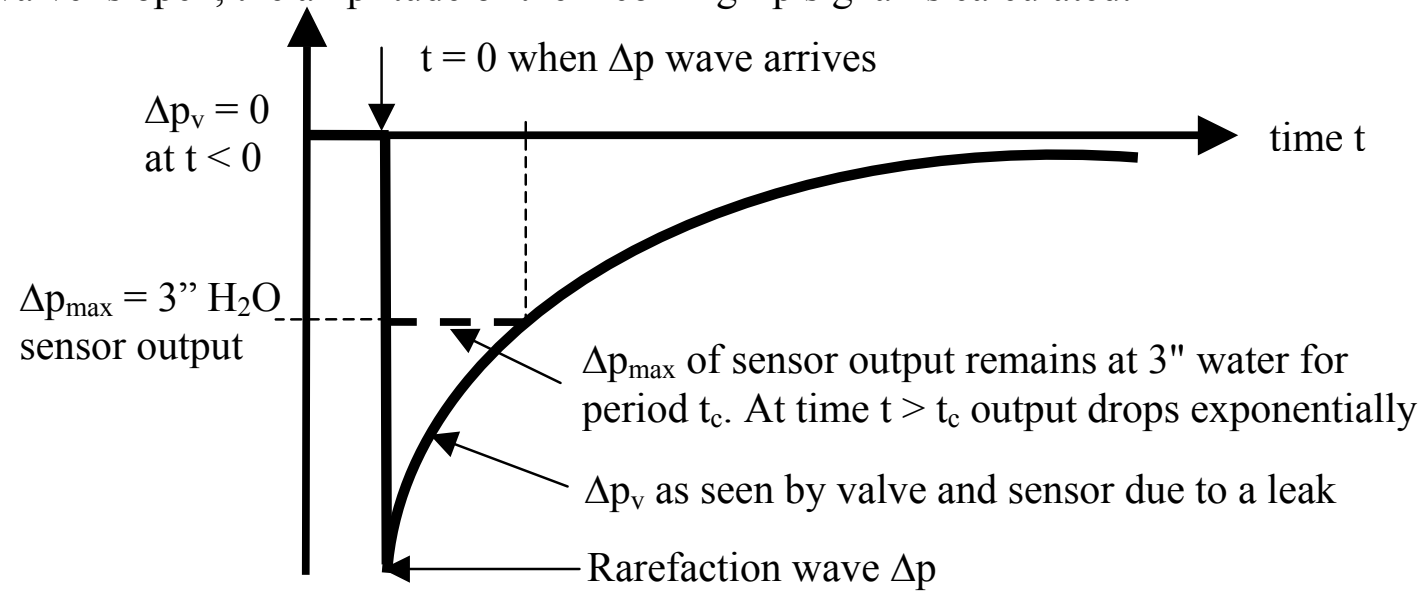

Figure 6 - Schematic of sensor response to a step function pressure transient. 


\section{C. - AERODYNAMIC STEP FUNCTION $\triangle$ P SENSOR RANGE AMPLIFIER}

A rarefaction wave $\Delta \mathrm{p}$ signal associated with a leak induces an instantaneous pressure drop $\Delta \mathrm{p}$ on one side of the differential pressure sensor. The two sides are connected via a one-liter accumulator and a needle valve. The sensor differential pressure signal bleeds off exponentially at a rate depending on the needle valve setting. The SFP10SSB color-coded needle valve is supplied with a factory calibration in terms of a flow coefficient $c_{\mathrm{v}}$ as a function of the number of turns $(\mathrm{N})$. In the range from 0 to 3 turns this is: $c_{v}=0.000003 * N^{7.5}$. At low $\mathrm{N}$, the flow through this valve is highly nonlinear because most of the pressure drop is dissipated by friction rather then by dynamic pressure in the valve passage. The factory specification suggests using this coefficient $c_{v}$ to calculate flow rate through this valve as a function of valve pressure difference $\Delta \mathrm{p}_{\mathrm{v}}$ (psia) at line pressure $\mathrm{p}$ (psi) with equation:

$Q(s c f h)=42.2 * c_{v} *\left(\frac{2 * \Delta p_{v} *\left(2 p-\Delta p_{v}\right)}{\rho / \rho_{\text {std.air }}}\right)^{0.5}$ As soon as the rarefaction wave of

magnitude $\Delta \mathrm{p}$ arrives, the valve pressure differential $\Delta \mathrm{p}_{\mathrm{v}}$ begins to drop exponentially in time $\mathrm{t}_{\mathrm{c}}$ to $\Delta \mathrm{p}_{\max }$ of sensor. During this time period $\mathrm{t}_{\mathrm{c}}$, the rate of outflow from the accumulator is controlled by the valve setting and pressure differential $\Delta \mathrm{p}_{\mathrm{v}}$. The velocity inside this valve is at very low Mach number because $\Delta \mathrm{p}_{\mathrm{v}}<<\mathrm{p}$ and the flow may be assumed incompressible at an equivalent velocity $V_{e}=\left(2 * \Delta p_{v} / \rho_{o}\right)^{0.5}$, with constant density $\rho_{\mathrm{o}}=\mathrm{p}_{\mathrm{o}} /(\mathrm{R} * \mathrm{~T})$ through an equivalent area $\mathrm{A}_{\mathrm{e}}\left(\mathrm{ft}^{2}\right)$ such that flow $\mathrm{Q}(\mathrm{scfs})=\mathrm{V}_{\mathrm{e}} * \mathrm{~A}_{\mathrm{e}}$. In above equation for $\mathrm{Q}(\mathrm{scfh})$, the term $\left(2 \mathrm{p}-\Delta \mathrm{p}_{\mathrm{v}}\right)$ may be replaced by $2 \mathrm{p}_{\mathrm{o}}$ as $\Delta \mathrm{p}_{\mathrm{v}}<<\mathrm{p}_{\mathrm{o}}$. Converting to consistent English units with $\mathrm{p}$ in (psfa), $\mathrm{Q}$ in ( $\mathrm{scfs}), \mathrm{V}_{\mathrm{e}}$ in $\mathrm{ft} / \mathrm{s}, \mathrm{A}_{\mathrm{e}}$ in $\mathrm{ft}^{2}$ and replacing $\rho_{\text {std.air }}$ with $0.002377 \mathrm{slug} / \mathrm{ft}^{3}$ find:

$$
Q(s c f s)=V_{e} * A_{e}=\frac{42.2 * c_{v}}{144 * 3600} *\left(\sqrt{\frac{2 * \Delta p_{v}}{\rho}}=V_{e}\right) * \sqrt{2 * p_{o}^{*} 0.002377}
$$

Dividing by $V_{e}$ gives equivalent valve opening area $A_{e}$ in terms of $c_{v}$ or valve turns $(N)$.

$$
A_{e}=0.0000056 * c_{v} * \sqrt{p_{o}}=0.168 * 10^{-10} * N * \sqrt{p_{o}}
$$

Next determine the time delay $t_{c}$ required for the accumulator to drop to within sensor maximum pressure $\Delta \mathrm{p}_{\max }=3$ inch water, after passage of a rarefaction wave of strength $\Delta \mathrm{p}$. During that time period $\mathrm{t}_{\mathrm{c}}$ the differential pressure sensor output will remain at $\Delta \mathrm{p}_{\max }$. From ideal gas eq. of state for isothermal outflow from accumulator of mass $m=\frac{p^{*} \mathrm{Vol}}{R^{*} T}$ find outflow rate: $\frac{d m}{d t}=\frac{d p}{d t} * \frac{V o l}{R^{*} T}$ or in terms of volume flow rate $\mathrm{Q}(\mathrm{scfs})$ : 
$-Q(\operatorname{scfs})=\left(\frac{1}{\rho}=\frac{R^{*} T}{p_{o}}\right) *\left(\frac{d m}{d t}=\frac{d p}{d t} * \frac{V o l}{R^{*} T}\right)=d p * \frac{V o l}{p_{o} d t}=-V_{e} * A_{e}$ or

While the pressure inside the accumulator drops, the velocity in the needle valve is:

$V_{e}=\sqrt{\frac{2 *\left(p-\left(p_{o}-\Delta p_{\max }\right)\right)}{\rho=p_{o} /(R * T)}}$ or $V_{e} A_{e}=\sqrt{\left(p-\left(p_{o}-\Delta p\right)\right)} * \sqrt{2 * R * T} * 0.0000056 * c_{v}$

Insert above and separating variables gives:

$\frac{d p}{2 * \sqrt{\left(p-\left(p_{o}-\Delta p\right)\right.}}=-\sqrt{\frac{R * T}{2}} * \frac{p_{o}}{V o l} * 0.0000056 * c_{v} * d t$

Integrating from time $0<\mathrm{t}<\mathrm{t}_{\mathrm{c}}$ and $\mathrm{p}_{\mathrm{o}}>\mathrm{p}>\left(\mathrm{p}_{\mathrm{o}}-\Delta \mathrm{p}+\Delta \mathrm{p}_{\max }\right)$ gives:

$$
\sqrt{\left(p-\left(p_{o}-\Delta p\right)\right.}||_{p_{o}}^{p_{o}-\Delta p+\Delta p_{\max }}=\sqrt{\Delta p}-\sqrt{\Delta p_{\max }}=\sqrt{\frac{R^{* T}}{2}} * \frac{p_{o}}{V o l} * 0.0000056 * c_{v} * t_{c}
$$

Defining the excess signal amplitude by

$$
A M P=\frac{\Delta p}{\Delta p_{\max }} \text { gives: } A M P=\left[1+\sqrt{\frac{R^{*} T}{2 * \Delta p_{\max }}} * \frac{p_{o}}{V o l} * 0.0000056 * c_{v} * t_{c}\right]^{2}
$$

\section{Time delay tc, during which $\Delta$ psensor remains at $\Delta$ pmax with needle valve 3 turns open}

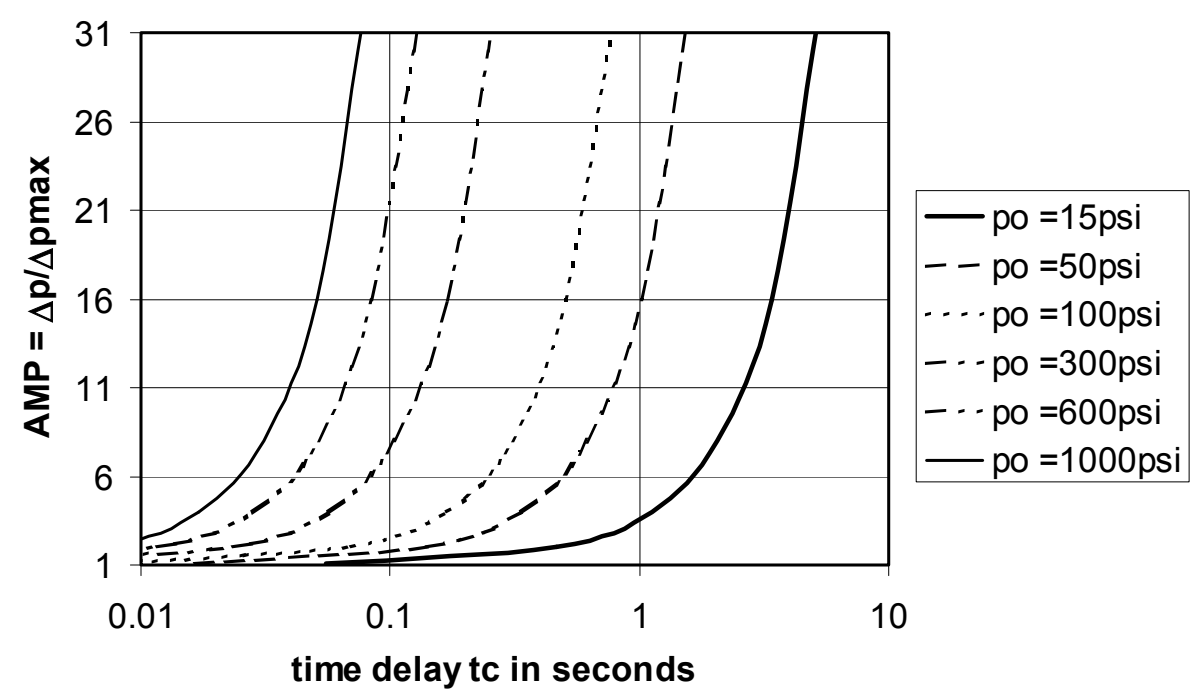

Figure 7 - Time delay $\mathrm{t}_{\mathrm{c}}$ in seconds, indicative of the $\Delta \mathrm{p}$ step function signal strength which equals: AMP times transducer $\Delta \mathrm{p}_{\max }=3$ " water range. 


\section{D. - AERODYNAMIC RAMP FUNCTION dp/dt SENSOR}

All step function acoustic waves degenerate to ramp function waves when traveling a long distance through a pipe due to wall friction. Therefore it is important to measure also $\mathrm{dp} / \mathrm{dt}=$ constant for such ramp type signals. Again as before one side of the Rosemont differential pressure sensor follows the transmission pipeline pressure while the other side has the needle valve plus accumulator in series with it. Thus a ramp type rarefaction wave produced by a rapidly formed significant leak, will cause the pressure on one side of the differential pressure sensor to drop just like the pipeline pressure but the side with the accumulator will lag behind a fixed $\Delta \mathrm{p}$ level, indicative of the magnitude of the $\mathrm{dp} / \mathrm{dt}$ signal. Note again change in pipeline gas density $\rho$ can be ignored or $\rho=\rho_{\mathrm{o}}=\mathrm{p}_{\mathrm{o}} /\left(\mathrm{R}^{*} \mathrm{~T}\right)$. Thus the flow rate through the needle valve

$$
\dot{Q}(s c f s)=A_{e} * \sqrt{\frac{2 * \Delta p_{v}}{\rho_{o}}}=-\rho_{o} *\left(\frac{d m}{d t}\right)_{\text {accumulator }}=-\rho_{o} *\left(\frac{d p}{d t} * \frac{V o l}{R * T}\right)_{\text {accumulator }}
$$

solving for unknown $\mathrm{dp} / \mathrm{dt}$ as a function of differential pressure sensor reading $\Delta \mathrm{p}_{\mathrm{v}}$ gives:

$$
\begin{aligned}
& \frac{d p}{d t}=\sqrt{\Delta p_{v}} *\left(\frac{R * T}{V o l} * \frac{A_{e} * \sqrt{2}}{\rho_{o}^{1.5}}\right) \text { where as before } A_{e}=0.0000056 * c_{v} * \sqrt{p_{o}} \text { or: } \\
& \frac{d p}{d t}=\sqrt{\Delta p_{v}} *\left(R^{*} T\right)^{1.5 *} *\left(\frac{0.0000056 * c_{v} * \sqrt{2} *}{\rho_{o} * V o l}\right) \text { for } 0<\mathrm{N}<3 \text { find } \mathrm{c}_{\mathrm{v}}=0.000003 * \mathrm{~N}^{7.5}
\end{aligned}
$$

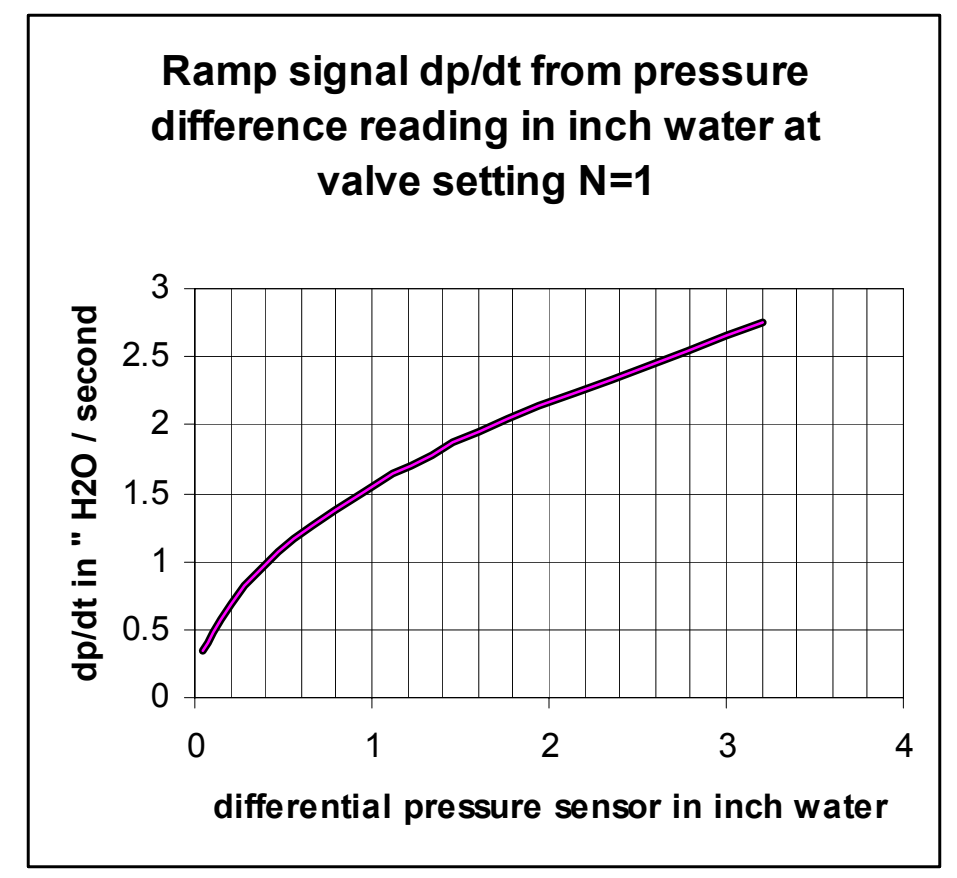

Figure 8 - Steady differential pressure reading with needle valve $\mathrm{N}=1$ turn open, indicating the $\mathrm{dp} / \mathrm{dt}$ ramp function signal strength in inch of water. 


\section{E. - DATA ACQUISITION}

The Omega DAQP-208 is a Type II PCMCIA data acquisition card with 4 differential or 8 single ended 12- bit A/D input channels (expandable to 128), with a maximum sampling rate of $100 \mathrm{kHz}$, and programmable gains of $1,2,4$, or 8 , which provide ranges of $\pm 1.25 \mathrm{~V}, \pm 2.5 \mathrm{~V}, \pm 5 \mathrm{~V}$, to $\pm 10 \mathrm{~V}$. A high gain option is also available providing gains of $1,10,100$ or 1000 , for ranges of $\pm 0.01 \mathrm{~V}, \pm 0.1 \mathrm{~V}, \pm 1 \mathrm{~V}$, to $\pm 10 \mathrm{~V}$ The DAQP-208 is also equipped with two 12-bit D/A output channels. The outputs can be updated individually when writing to the corresponding D/A port, or simultaneously when a synchronization signal comes. The DAQP-208 has a $2 \mathrm{~K}$ data FIFO that will significantly reduce CPU overhead, and a scan FIFO of 2048 entries, each of which can be specified with an input channel and it's associated gain. It has a selectable scan speed of $10 \mathrm{~ms}$ to $40 \mathrm{~ms}$ per channel. Data acquisition may be initiated by a trigger signal or by using the DAQP-208's pre-trigger capability. The DAQP-208 has a 24-bit auto-reload pacer clock which generates accurate sampling rates from $0.006 \mathrm{~Hz}$ to $100 \mathrm{k} \mathrm{Hz}$ using an internal or external clock source. The pacer clock is actually a 24-bit auto-reload frequency divider. It contains a 24-bit divisor register, a 24-bit counter, and internal clock pre-scalar and a clock source multiplexer. The DAQP-208 also has a 16-bit timer/counter with an auto-reload and readout latch, which provides independent timing for the D/A channels, and operates with internal or external clock source and gate controls. The DAQP-208 is compatible with the DasyLab signal-processing package. Signal Conditioning/Expansion is possible through the SignalPro line of signal conditioners. These signal conditioners allow the DAQP-208 to read most process sensors and provides channel expansion up to 256 inputs. Drivers are also included for numerous third-party software packages including Labtech Notebook, DasyLab support, LabVIEW, and SnapMaster.

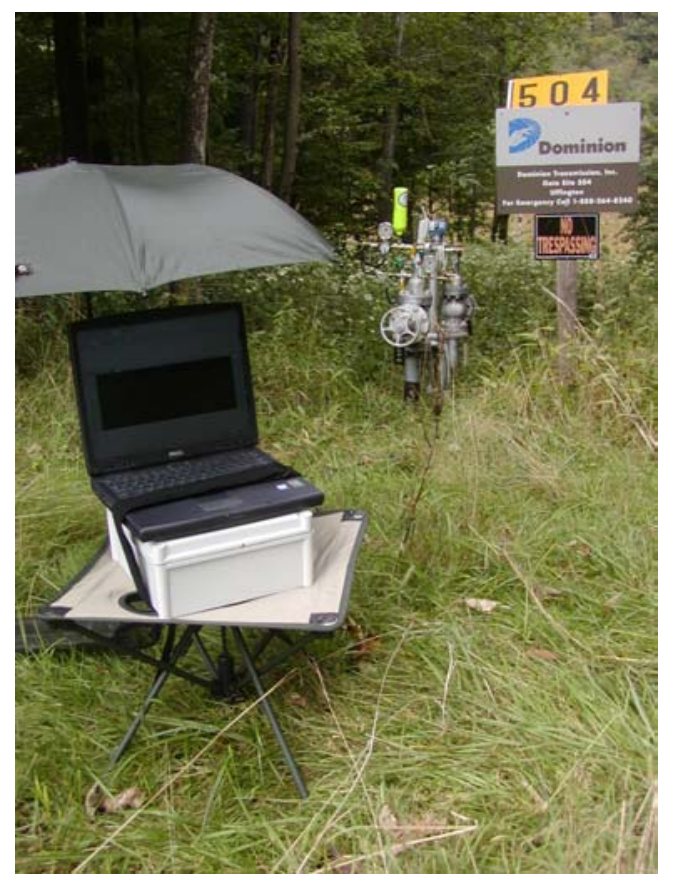

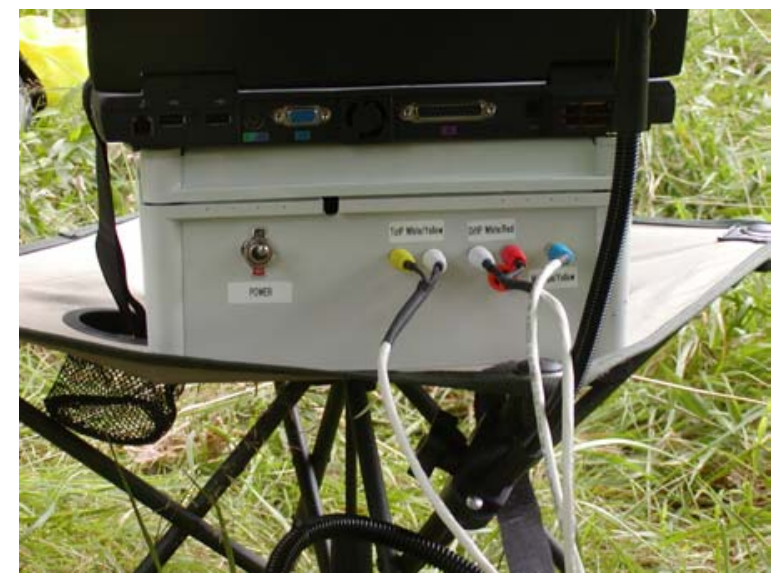

Figures 9 \& 10 - PAMP and data acquisition unit installed on a natural gas transmission line in West Virginia. Computer, shielded cables and plumbing tree are clearly visible. 


\section{RESULTS AND DISCUSSION}

Preliminary field and laboratory testing have indicated that the WVU PAMP has the ability to detect and record the three signal types associated with leaks or third party damage. The three-signal types are the acoustic signature, the step function associated with the onset of a leak or third-party damage and the ramp function associated with the attenuation of the initial step function signal. With a weight of only 36 pounds and it's modular rugged construction, the PAMP is truly field portable. Set up times in recent field tests show that the system can be set up in less then 30 minutes. The future incorporation of remote monitoring equipment will allow long turn onsite monitoring by multiple units.

\section{CONCLUSIONS}

The second generation Portable Acoustic Monitoring Package (PAMP) has proven to satisfy all the expected requirements. It is easy to carry and install in the field. It satisfies all the safety features specified by Dominion Transmission Inc. engineers, before permitting WVU technicians to test the PAMP on lines operating at less than 1000 psi. The PAMP plumbing tree is very rugged, weather proof and fairly inexpensive to duplicate at an estimated cost of $\$ 2500$. The laptop data acquisition system allows online data frequency analysis. The newly developed signal range amplifier has proven to be an essential tool, which allows recording a greatly increased range of measurable pressure pulse amplitudes without loss in sensor sensitivity! Currently the use of PAMP has been limited to cataloging transmission line noise sources. The next phase will include some permanent PAMP installations with remote wireless data monitoring.

Dominion Transmission has identified two-transmission line systems, which are suitable for background noise cataloging due to accessibility and steady line pressures. One system is between Bridgeport and Morgantown in West Virginia. This system has a number of access ports and a line pressures between 200 and 350 psi. The other system is in the vicinity of New Cambridge, Ohio. The system near New Cambridge has a fairly constant line pressure of approximately 850 psi. A unique feature of the Ohio system is that it contains one main transmission line, which was installed in a straight line for at least 30 miles. This 30 -mile line segment has 2 or 3 access points where one or two PAMP units can be installed with remote monitoring. This unique combination of a straight line, a fairly constant line pressure, easy access and a known noise source (from a Gilmer reciprocating compressor station) will allow noise attenuation effects in an active transmission line to be measured. Table 1 gives designated observation sites for background noise cataloging. 


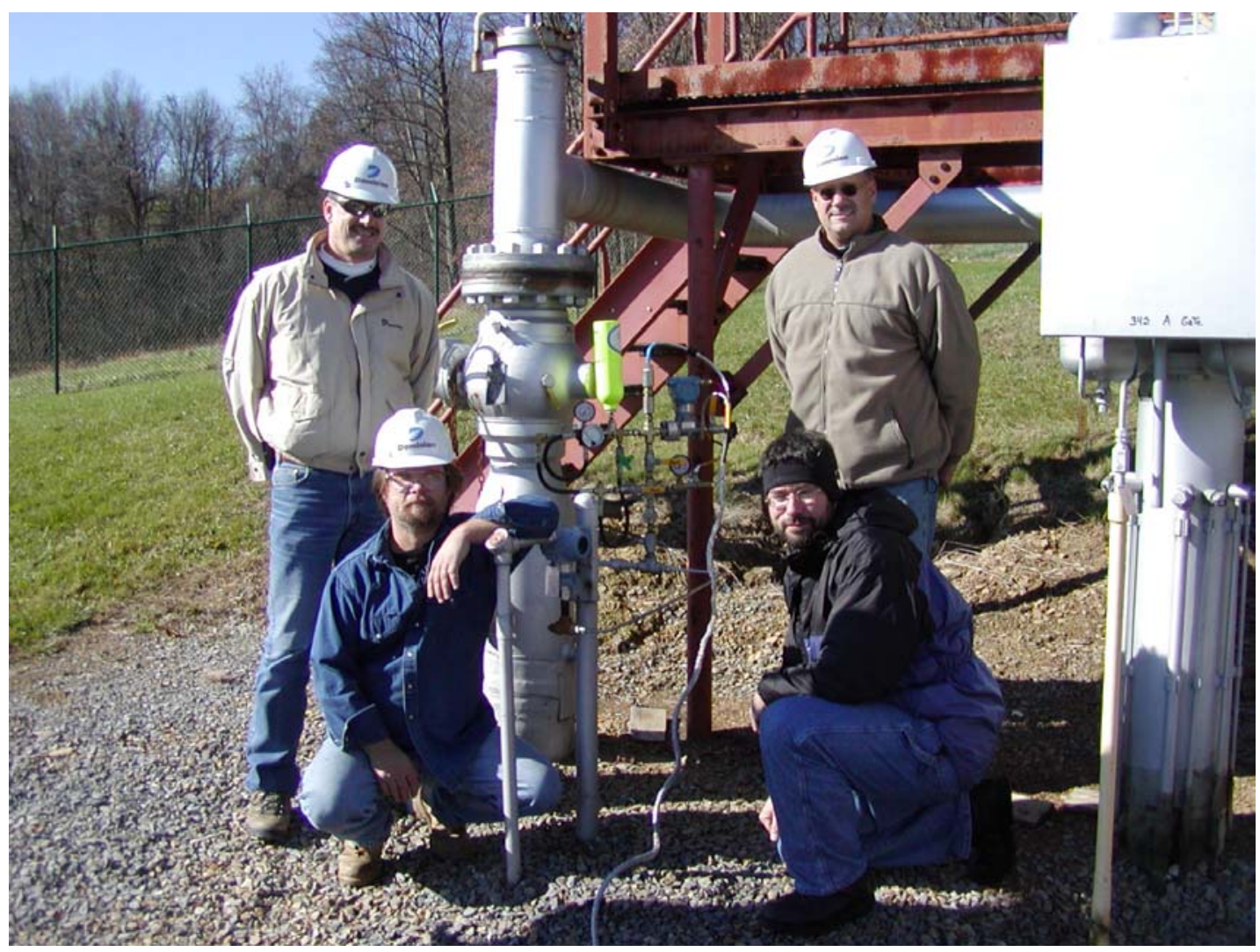

Figure 11 - Dominion Transmission Inc. 900-psi 24-inch transmission line access near Waynesburg, PA. Engineers Jim Parsons, Bill Ruffner, John Hart and WVU research assistant Richard Guiler next to the "Portable Acoustic Monitoring Package" (PAMP). 


\begin{tabular}{|c|c|c|c|}
\hline Noise Source & Location & Pressure & Special Considerations \\
\hline $\begin{array}{c}\text { Reciprocation } \\
\text { Compressor } \\
\end{array}$ & \begin{tabular}{|c|} 
North Summit \\
Storage Facility, PA
\end{tabular} & $>3000 \mathrm{psi}$ & $\begin{array}{l}\text { Due to excessive pressures only pipe wall and } \\
\text { iairborne signals will be recorded. }\end{array}$ \\
\hline $\begin{array}{c}\text { Reciprocation } \\
\text { Compressor }\end{array}$ & $\begin{array}{l}\text { Salt Well Road WV } \\
\text { Compressor Station, }\end{array}$ & \begin{tabular}{|c|}
$\sim 200-350$ \\
psi
\end{tabular} & $\begin{array}{l}\text { Record signal at typical RPM setting and } \\
\text { characterize }\end{array}$ \\
\hline $\begin{array}{l}\text { Reciprocation } \\
\text { Compressor }\end{array}$ & $\begin{array}{l}\text { Gilmer Compressor } \\
\text { Station, OH }\end{array}$ & $\sim 850 \mathrm{psi}$ & $\begin{array}{l}\text { Record Data at } 2-3 \text { locations on the } \\
\text { transmission line as well as airborne and pipe } \\
\text { wall compressor signals. Use signals recorded } \\
\text { on the transmission line to study attenuation } \\
\text { and signal Doppler effect due to gas flow. }\end{array}$ \\
\hline $\begin{array}{c}\text { Turbine } \\
\text { Compressor }\end{array}$ & Waynesburg, PA & $>2000 \mathrm{psi}$ & $\begin{array}{l}\text { Due to excessive pressures only pipe wall } \\
\text { i airborne signals will be recorded. }\end{array}$ \\
\hline $\begin{array}{l}\text { Acoustic Flow } \\
\text { Meter }\end{array}$ & $\begin{array}{l}\text { Salt Well Road WV } \\
\text { Compressor Station, }\end{array}$ & $\begin{array}{c}\sim 200-350 \\
\text { psi }\end{array}$ & To characterize flow noise \\
\hline $\begin{array}{l}\text { Rotary Flow } \\
\text { Meter }\end{array}$ & $\begin{array}{l}\text { Salt Well Road WV } \\
\text { Compressor Station, }\end{array}$ & $\begin{array}{c}\sim 200-350 \\
\text { psi }\end{array}$ & To characterize flow noise \\
\hline $\begin{array}{l}90 \text { degree turn in } \\
\text { Line }\end{array}$ & $\begin{array}{l}\text { Salt Well Road WV } \\
\text { Compressor Station, }\end{array}$ & $\begin{array}{c}\sim 200-350 \\
\text { psi }\end{array}$ & To characterize flow noise \\
\hline Tee in line & $\begin{array}{l}\text { Salt Well Road WV } \\
\text { Compressor Station, }\end{array}$ & $\begin{array}{c}\sim 200-350 \\
\text { psi }\end{array}$ & To characterize flow noise \\
\hline Gate Valve & $\begin{array}{l}\text { Salt Well Road WV } \\
\text { Compressor Station, }\end{array}$ & $\begin{array}{c}\sim 200-350 \\
\text { psi }\end{array}$ & To characterize flow noise \\
\hline Gate Valve & $\begin{array}{l}\text { Salt Well Road WV } \\
\text { Compressor Station, }\end{array}$ & $\begin{array}{c}\sim 200-350 \\
\text { psi }\end{array}$ & $\begin{array}{l}\text { The record signal associated with opening and } \\
\text { closing of a main line valve. }\end{array}$ \\
\hline $\begin{array}{l}\text { Gas blow off } \\
\text { through } 1 / 2 " \text { port }\end{array}$ & $\begin{array}{l}\text { Salt Well Road WV } \\
\text { Compressor Station, } \\
\end{array}$ & \begin{tabular}{|c|}
$200-350$ \\
psi
\end{tabular} & To characterize flow noise \\
\hline $\begin{array}{c}\text { Gas blow off } \\
\text { through } 1 / 2 " \text { port }\end{array}$ & $\begin{array}{l}\text { Gilmer Compressor } \\
\text { Station, OH }\end{array}$ & $\sim 850 \mathrm{psi}$ & $\begin{array}{l}\text { Record Data at } 2-3 \text { locations on the } \\
\text { transmission line as well as airborne and pipe } \\
\text { wall compressor signals. Use signals recorded } \\
\text { on the transmission line to study attenuation } \\
\text { and signal Doppler effect due to gas flow. }\end{array}$ \\
\hline $\begin{array}{l}\text { Various leak } \\
\text { geometries }\end{array}$ & $\begin{array}{l}\text { West Virginia } \\
\text { University, } \\
\text { Supersonic Wind } \\
\text { Tunnel, WV }\end{array}$ & $0-200 \mathrm{psi}$ & $\begin{array}{l}\text { Record and characterize noise generated by } \\
\text { various leak geometries at various pressures } \\
\text { and flow rates. }\end{array}$ \\
\hline
\end{tabular}

Table 1 - West Virginia University initial test schedule to record gas transmission line typical noise sources using the PAMP 


\section{REFERENCES}

Bassim, M.N., and Tangri, K.'Leak Detection in Gas Pipelines using Acoustic Emission", Proceedings from International Conference on Pipeline Inspection, Edmonton Alberta, pp. 529-544, Canada, 1984.

Crouch, A. E., Burkhardt, G. L., "The Non-Linear Harmonic Method for Detection and Characterization of Mechanical Damage in Pipelines. Int. Chem. and Pet. Industry Inspec. Tech Topical Conf, Houston Texas June 1999.

Gilmore R. E. “Lost Gas Speaking,” Gas Age-Record 1-4 ,July 6, 1935.

Huebler, J.E., "Detection of Unauthorized Construction Equipment in Pipeline Right of Ways", Presentation given at U. S. Department of Energy, National Energy Technology Center Natural Gas Infrastructure Reliability Industry Forums, Morgantown, WV, September 2002.

Jolly, W.D., Morrrow, T.B., O’Brien, F.F., Spence, H.F., and Svedeman, S.J., "New Methods for Rapid Leak Detection in Offshore Pipelines", Final Report for U.S. Department of the Interior Minerals Management Service, pp. 1-84, April 1992.

Kennedy, J.L., “Oil and Gas Pipeline Fundamentals” Penn Well Books, Tulsa Oklahoma, 1984.

Larson D.B. "Practical Use of Sound Amplifiers in Gas Leak Detection,” Proc. Pacific Coast Gas Association 30,81-82, 1939.

Leis, B.N., Francini, R.B., Stulen, F.B., Hyatt, R.W., and Norman, R., "Real Time Monitoring to Detect Third Party Damage", Proceedings of the Eighth International Offshore and Polar Engineering Conference, Montreal Canada, pp. 34-38, May 1998.

Parker, John, "Acoustic Detection and Location of Leaks in Underground Natural Gas Distribution Lines”, John Hopkins APL Technical Digest, V2, N2, Apr-Jun, pp. 90-101, 1981.

Qian, Shie, "Introduction to Time Frequency and Wavelet Transforms", Prentice Hall 2002.

Richardson, R.B., Listening For Leaks, Gas Age-Record, 47-48, July 30, 1935. 
Rocha, M. S., "Acoustic Monitoring of Pipeline Leaks" Paper \# 89-0333, ISA, 1989

Shack, W.J., Ellingson, W. A., and Youngdahl, C.A., "Development of a Noninvasive Acoustic Leak Detection System for Large High Pressure Gas Valves", ISA

Transactions, Vol. 19, No. 4, pp. 65-71, 1980.

Smith, O. L. "The Soundograph System for Gas Leak Detection," Gas Age-record 381383(Apr 15, 1933)

Wylie, E. B., and Streeter, V. L. with Suo, L., "Fluid Transients in Systems" Prentice Hall, 1993.

Zhang, Jun, "Designing a Cost Effective and Reliable Pipeline Leak Detection System", Pipeline Reliability Conference, Houston, USA, November 19-22, 1996.

\section{ADDITIONAL SOURCES OF INFORMATION}

DAQP-208 Type II PCMCIA data acquisition card, product data sheets, D1-31 and D132, Omega scientific instruments, 2002 http://www.omega.com/DAS/pdf/DAQP-208.pdf.

Rosemount Model 3051 product data sheets, Rosemount Comprehensive Product Catalog, 2002-2003 Edition, http://www.emersonprocess.com\rosemount.

\section{Report Distribution:}

1) Electronic via CD-ROM in PDF Format, file name 41324R05.pdf Labeled:

DOE Award \# DE-FC26-02NT41324

5th Quarter Report

West Virginia University

Dr. John Loth

304-293-4111 ext. 2343

2) One Paper Copy and the above CD-ROM To:

NETL AAD Document Control BLDG. 921

U.S. Department of Energy

National Energy Technology Laboratory

P.O. Box 10940

Pittsburgh, PA 15236-0940 